\title{
In the World of Medical Alphabet Soup-"Will A Workable EMR or EHR Please Stand Up?"
}

\author{
Ralph Grams
}

Published online: 1 October 2011

(C) Springer Science+Business Media, LLC 2011

The role of medical records has never been more intriguing than in the last three years when the US government has decided to throw billions of dollars at the problem in hopes of finding a suitable solution. To complicate the issue, we have a complete divergence in goals and objectives for the creation and operation of this new electronic marvel.

The physicians are still stuck with a medieval understanding of doing no harm and looking after the best interests of the patient [1]. In the other corner are the insurance carriers and big government who are focused on the automation of records so that they can minimize fraud, cut expenses, and increase control. These two points of view are diametrically opposed on the issues of ordering and modes of treatment.

The physician views each patient as a unique entity that needs services customized for that case. The government and insurance industry sees healthcare as an assembly line where there is a uniform product and a uniform delivery and application process. They are focused on rationing care to minimize expenses and making the treatment decisions at a central point where statistics and cost benefits are calculated. The closer we get to a single-payer system the more centralized will be the systems operation. The singlepayer system and the rationing of care are structurally linked and not easily separated.

Under Obamacare, as you add a broader scope of patients to the pool of eligible clients, the demands increase to pick and choose winners and losers. Quality of life panels will need to be established to decide who is given

R. Grams ( $\square)$

Pathology and Medical Informatics,

College of Medicine University of Florida,

Gainesville, FL 32610, USA

e-mail: kqinc@aol.com the therapy to live and who gets cut off [2]. Do the aged take second place and the youth prevail? Do the handicapped get left in wheel chairs while the productive get bone marrow transplants?

Under a single-payer system these types of discussions can be predicted with certainty. Under the Obama healthcare system, we are being forced into a single-payer system. That was the President's choice during the presidential election debate. He favors centralized control of all services, providers and hospitals.

You can now see why this move to establish a uniform electronic medical record is so intense. This whole singlepayer system depends on herding the entire medical community into one corral and keeping them penned. The obvious question is: How have they enticed physicians to participate?

Answer: They are spending tax dollars to encourage doctors to automate their offices and install governmentapproved systems that will accomplish their ultimate goals. This "Trojan Horse" program will have a whole series of intended consequences that are all negative for the doctors. As they herd the health providers into this electronic pen, they are looking at every claim and every bill with legal and automated teeth to deny claims. Doctors will be asked to prove that the patient has improved and that they are better now than when they started. They are going to be grading the physician about their billing and performance so that patients can see a ranking of government based criteria [3]. Each patient will be structured into an approved treatment protocol and the doctor will be doing nothing more than following the government mandates for uniform patient care. The termination of care will be made at the national level and the local control of patient choice will disappear.

In the rush to implement both Obamacare and this new EHR program, no provisions were made for malpractice 
reform. Was this a mistake or was it done to support the legal lobby that runs Congress and most of Washington. These attorneys have a huge cash flow to protect and there is no action being taken to make this any different than it is now. In fact, it could get much worse. These new EMRs and EHRs are often so poorly constructed that they are not even readable by an average physician. The progress notes they produce are filled with things that were not said or implied. The doctor is often hard pressed to defend his own documents. This is a huge hole in our systems and will result in lawsuits and more claims in the near future [4].

Now there are many people who think these are good and excellent options. They don't want to keep people alive who are not productive and are a burden on society. These people usually support population control and abortion. This is called the progressive socialist agenda and has been alive and well for decades. This philosophy has now been ingrafted into Washington and the nation is currently headed full speed in this direction. This is what was called "Change" in the last presidential election: "A new way of living and a new formula for social interaction." This new social "constitution" also implies a redistribution of wealth so that those who are poor get what belongs to the rich. They want to create an even playing field for all. This means that we are all entitled to: government healthcare, union representation, government jobs, government housing and government pensions. As you inspect this "new" social contract you will note that it directly copies the Constitution of the Soviet Union. This "new idea" is merely the reintroduction of Marxism dressed up as "Change".

As we move down this progressive road to "change", let's look at several of the fruits of this new technology and its operation.

EMRs (electronic medical records) and EHRs (electronic health records) are two code words that talk about the same condition. The goal is to move the entire medical record from clinics and hospitals onto a computer storage device so that everything about an individual is accessible at one location. These records include your billing information and all your personal and financial data. Sounds like a great idea, but there are some drawbacks:

If all your data is located in one place, what happens if the data is copied or stolen and then sold to others for criminal purposes? You the patient are stuck with a terrible mess and your identity will be compromised and your credit and finances could be destroyed. Has this happened?

Here are a partial list of groups that have lost or compromised electronic medical records in the last year along with their fines: Massachusetts General Hospital — $\$ 1$ million dollars [5]; Cignet $— \$ 4.3$ million dollars [6]; Triple-S in Puerto Rico lost 400,000+ medical records - the full fines are not known [7]; Keystone Mercy Health Plan compromised 280,000 medical records compromised-no fine assessed yet [8]; University of Tennessee breaches 8000 medical records - no fine assigned yet [9]; California has seven institutions that are being fined for lost or compromised records with a total so far of $\$ 540,000.00$ [10]. These are just recently published data and there are many more problems to be anticipated as the volume of records increases and the scope of their exposure expands. As these records move into the government sector they will be used by many contractors and government employees who will be able to open new doors for hackers and Internet thieves. This new massive federal database will be a huge target for many who could use this data for their personal gain [11]. We can't even protect our State Department and government emails from being published on WikiLeaks! How will we ever keep this massive database secure??

A second concern with this new medical records initiative is the lack of proven benefit from this type of massive investment. A recent study from Stanford University and published in the Archives of Internal Medicine shows minimal benefit to patient care from the use of electronic health records [12]. The obvious question to ask is why are we spending so much money to force the medical community into this rigid structure if it does not improve patient care? The answer is very simple. The government is not primarily interested in patient care but in controlling costs and controlling physician behavior. The only way to stop the spending is to stop the doctor from writing orders and have his orders disapproved. Here is this basic conflict again showing up in our government's actions. They are pulling the medical professional into a socialist system with tight governmental controls.

As we move along this production line of government controls and mandates, we approach another acronymMU. No, it is not the cry of a cat, but a new term called "meaningful use". The government has drafted a set of guidelines that all EHR and EMR providers must meet if they are going to get their clients money from the government. All systems must now be certified for MU. The guidelines have almost nothing to do with patient care and physician improvement, but deal with transmitting data in a uniform way so that federal computers can compare and "process" all this new data $[13,14]$. This is all about data mining and trying to get something out of nothing. The hope is that if you get enough data you can set standards and guidelines for everyone and discover all kinds of new associations for medical use. Unfortunately, this is a totally misguided expectation. When you have a wide range of different systems using medical terminology that is difficult to grade, you will get a wide range of interpretations which are may not be related or controlled. The old adage is still true: garbage in will eventually get you garbage out. We leaned a long time ago that only tightly controlled studies with every variable defined and supervised could be used 
for clinical trials. Even these controlled studies have troubles and often need to be duplicated to be sure of the final results. To expect a large pile of medical records with minimal controls in place to result in meaningful end result is irrational exuberance. Analyzing demographic data is one thing, but trying to compare treatment results and patient outcomes will be impossible. Every patient is unique and has a unique response to a treatment plan and medications. Tightly controlled clinical studies are needed for these types of questions and not a national repository of random medical records.

When we look at compliance within the medical community, we can see that this process is not going well. As of last May, 2010, a report done on EHRs and EMRs shows that $56 \%$ of all doctors have no system at all. $38 \%$ have a partial or minimal system and only $6 \%$ have what is considered a fully functioning EMR [15]. The largest suppliers of these systems are all in the process of installing and testing their systems so there is now real performance or success data to report. Billions of dollars are being poured into this process by hospitals across the nation and each one has a huge staff and a wide range of data processing skills now on the hospital payroll. There is a great concern over the MUs that are being forced on the vendors and hospitals by the government and whether this will all work. All the funding and development time of every vendor is now focused on these MUs and patient oriented requirements are being ignored and minimized [16].

We are investing in the most extensive reorganization of medicine in modern history. We don't have a clear model of success to follow and there are no operational prototypes that have been fully tested. Perhaps the most widely used and most widespread system in the United States is the VA EHR hospital system (Vista) which has been able to expand and grow over the past 15 years. This is not the model being followed by the core staff in Washington in charge of this social experiment. There was never time given to study this concept and offer a scalable model. This process was jammed through with the Obama budget and nobody had any time to review what was being proposed. It is a great example of midnight legislation done behind closed doors. The classic comment for all times must be: "You need to pass it so you can see what is in it". Let's hope this is better than what they got in England with their national health system automation project.

\section{References}

1. Wax, C. M., EHRs, insurance, and government: When did we lose sight of the patient? Med. Econ., December 3, 2010.

2. Seidl, J., British socialized healthcare official Dr. Daphne Austin says: Some premature babies should be left to die. BBC programThe Price of Life. March 7, 2011.

3. Monegain, B., CMS wrestles with how to compare physicians. Healthcare IT News. October, 29, 2010.

4. Arvantes, J., Health care reform law fails to provide remedies for medical malpractice. AAFP News Now, October 20, 2010.

5. Merrill, M., Medicaid data breach "like and onion". Healthcare IT News. October 26, 2010.

6. www.hhs.gov/news/press/2011pres/02/20110222a.html.

7. www.hhs.gov/news/press/2011pres/02/20110224b.html.

8. www.healthdatamanagement.com/news/breach-blues-riconotification-hitech-41409-1.html.

9. www.healthdatamanagement.com/news/breach-tennesseenotification-hitech-hippa-privacy-41404-1.html.

10. www.healthdatamanagement.com/news/california-fines-privacyviolations-hospitals-41405-1.html.

11. Vijayan, J., Privacy advocates fear massive fed health database. Computerworld. November 4, 2010.

12. Romano, M. J., Stafford, R. S. Electronic health records may not improve care quality. Arch. Intern. Med., January 26, 2011.

13. www.healthdatamanagement.com/news/onc-meaningful-use-ehrclarification-41647-1.html.

14. Clark, C., Meaningful use tops healthcare industry challenges for 2011. HealthLeadersmedia, December 20, 2010.

15. Thorman, C., HER software market analysis. Software Advice, May 14, 2010.

16. Ledue, C., Survey: Physicians unhappy with healthcare reform measures. Healthcare Finance News, November 19, 2010. 